\title{
Westerly jet stream and past millennium climate change in Arid Central Asia simulated by COSMO-CLM model
}

\author{
Bijan Fallah $^{1} \cdot$ Sahar Sodoudi $^{1} \cdot$ Ulrich Cubasch $^{1}$
}

Received: 18 November 2014 / Accepted: 17 April 2015 / Published online: 5 May 2015

(c) Springer-Verlag Wien 2015

\begin{abstract}
This study tackles one of the most debated questions around the evolution of Central Asian climate: the "Puzzle" of moisture changes in Arid Central Asia (ACA) throughout the past millennium. A state-of-the-art Regional Climate Model (RCM) is subsequently employed to investigate four different 31-year time slices of extreme dry and wet spells, chosen according to changes in the driving data, in order to analyse the spatio-temporal evolution of the moisture variability in two different climatological epochs: Medieval Climate Anomaly (MCA) and Little Ice Age (LIA). There is a clear regime behavior and bimodality in the westerly Jet phase space throughout the past millennium in ACA. The results indicate that the regime changes during LIA show a moist ACA and a dry East China. During the MCA, the Kazakhstan region shows a stronger response to the westerly jet equatorward shift than during the LIA. The out-of-phase pattern of moisture changes between India and ACA exists during both the LIA and the MCA. However, the pattern is more pronounced during the LIA.
\end{abstract}

\section{Introduction}

\subsection{The prerequisite for studying the climate in ACA}

Previous studies suggest that the recent warming trend is very likely to be human-induced (Santer et al. 1996; Hegerl

Bijan Fallah

bijanf@zedat.fu-berlin.de

1 Institut für Meteorologie, Freie Universität Berlin, Carl-Heinrich-Becker-Weg 6-10, 12165 Berlin, Germany et al. 1996; Stocker et al. 2013; Ramaswamy et al. 2006; Santer et al. 2003). The evolution of future global climate change has become one of the main concerns during the twenty first century. Central Asia, one of the largest deserts of the globe, is likely to be extremely vulnerable to the future warming (Chen et al. 2010). Recurring climatic phenomena can have a large influence on societies, economies, and human health, with extreme events potentially leading to crises of some kind. Extreme drought events, which affect extended areas and persist over a prolonged period, are defined as "exceptional drought events" (Shen et al. 2007). They may affect the economy, environment, and society of densely populated areas in Asia, hence there is an urgent need to address this issue for planning and securing the future mitigation and adaptation strategies under global warming scenarios.

An investigation of moisture variability of the past millennium will help us to understand how the climate system responded to the natural forcings over a period of time longer than the available observational data. This will lead to the improvement of the future climate simulations. Various proxy data make the past millennium the best documented historical climate period. Despite the existence of long-term climate reconstructions, the regional hydroclimatic change in ACA over the past millennium is poorly understood. Our knowledge about the sensitivity of the severe climate conditions (e.g., droughts, floods, etc.) to changes in climate forcing is mostly limited to the modern instrumental records (Easterling et al. 2000). The published climate reconstructions like the Monsoon Asia Drought Atlas (Cook et al. 2010) are based on proxy data which are not homogeneously distributed over the Asia. The analysis of local effects is a challenging approach when using such data, as the time resolution of proxies does not allow the investigation of inter-annual and seasonal changes. 
Previous studies based on different proxy data show that there is an out-of-phase behavior in moisture changes between the ACA and monsoon Asia (Chen et al. 2008; Chen et al. 2010; Cook et al. 2010; Fallah and Cubasch 2015; Polanski et al. 2014). According to Chen et al. (2010), this out-of-phase relation is more evident during the LIA. They proposed that the strengthening and southward shift of the westerly jet stream may have contributed to the moist LIA in the ACA. Sato et al. (2007) have studied the origins of water vapor over ACA in the recent climate. They concluded that the westerly circulations are major drivers of moisture changes in ACA. Lioubimtseva et al. (2005) concluded that the cyclones which originate from Mediterranean are transported by westerly jet stream into the ACA.

\subsection{Regime behavior in the climate system}

According to Lorenz (1969), the large-scale dynamics make the atmospheric long-term predictions possible. His fundamental work introduced application of the chaos theory in the atmospheric studies. He suggested that the atmosphere, which is a nonlinear system, may present deterministic regime behavior that is conditional to random changes (Slingo and Palmer 2011). Palmer (1993) have introduced the concept of extended-range atmospheric predictions by using the Lorenz convection model (Slingo and Palmer 2011). He showed that the climate response is predictable, even when a weak forcing in the Lorenz equation was included. Following this concept, Ruti et al. (2006) used NCEP-NCAR reanalysis and 40-year European Centre for Meduim-Range Weather Forecasts (ECMWF) Re-Analysis (ERA-40) to show that although the extra-tropical troposphere is extremely chaotic, the subtropical jet strength shows a bimodal regime behavior. In this paper, we use a $\mathrm{RCM}$ to study the high resolution regional response of the climate to the forcings of the past millennium.

\subsection{Regional climate modeling}

Along with the Global Circulation Models (GCMs), RCM simulations can contribute to a better understanding of the impact of extreme climate regimes on past environmental changes (Diffenbaugh et al. 2006). Due to the highly complex topography of Central Asia, which is not well represented in coarse-resolution GCMs, RCM simulations provide more information about the small scale moisture changes under different boundary conditions. Additionally, proxy reconstructions present regional climatic variability which is not resolved by GCM simulations (Thompson and Anderson 2000).

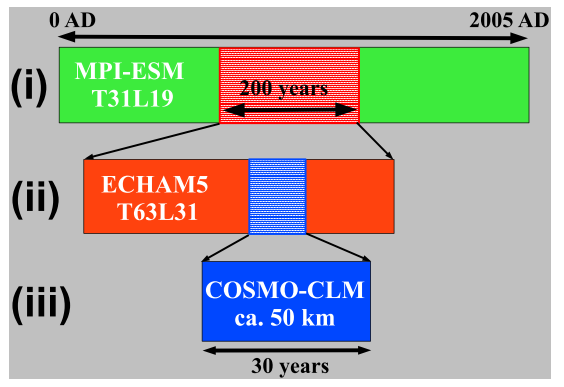

Fig. 1 Schematic of simplified approach of global (green and red) and regional (blue) climate simulations for the past Millennium 8002005 AD: (i) Millennium Experiment using fully coupled AOGCM in T31L19 spatial resolution. (ii) Atmosphere-only 200 year time slices experiments using ECHAM5 model at T63L31 resolution. (iii) High resolution regional climate model simulations with COSMO-CLM in a $50 \mathrm{~km}$ spatial resolution for 30-year time slices

This study tackles important subjects for which there is up to now mainly controversial evidences. Here, the sensitivity of extreme moisture events to climate of the past millennium is tested with a focus over Central Asia. First, the model set up is presented in Section 2 followed by results in Section 3. Finally, conclusions and discussions are presented in Section 4.

\section{Data and methods}

The general approach of the climate simulations for the past millennium presented here encompasses a three step hierarchy of model simulations (Fig. 1). The leading two steps are similar to the framework of simulations presented in Polanski et al. (2014), and the third one consists of additional RCM simulations which are driven by the Atmosphere only General Circulation Model (AGCM) runs. The general three-step framework works as follows: (i) a fully coupled atmosphere-ocean-land surface-bio-geochemistry global model of Max Planck Institute for Meteorology Earth System Model (MPI-ESM) for the entire past millennium (1206 model years), consisting of an atmospheric model, the European Centre/HAMburg version5 (ECHAM5) at a course spatial resolution of T31 (ca. $3.7^{\circ} \times 3.7^{\circ}$ ) (Roeckner et al. 2006), and an oceanic one, the Max Planck Institute Ocean Model (MPIOM) at a spatial resolution of GR3.0 (ca. $3.0^{\circ} \times 3.0^{\circ}$ ) are chosen from a set of ensemble members (for more details about the model selection, refer to Polanski et al. (2014) and Fallah and Cubasch (2015)), (ii) the ECHAM5 AGCM is selected at a higher spatial resolution of T63 (ca. $1.8^{\circ} \times 1.8^{\circ}$ ) for two different time slices (e.g., MCA and LIA) with a length of 200 years and (iii) a high spatial resolution RCM (ca. $0.5^{\circ} \times 0.5^{\circ}$ ) for 31 -year timeslices. The sea surface temperature and sea ice cover data for 
Table 1 RCM's time slices

\begin{tabular}{lll}
\hline Period & Wet & Dry \\
\hline MCA & $1060-1090$ & $960-990$ \\
LIA & $1615-1645$ & $1645-1675$ \\
\hline
\end{tabular}

AGCM simulations in step (ii) are taken from the coupled simulation of step (i) (Table 1).

Here, the AGCM runs of the past millennium from step (ii) are used as the driving model for RCM time-slice simulations. For the higher resolution simulations, the COSMO-CLM (CCLM) model version $4.8 \mathrm{clm} 17$ (Steppeler et al. 2003; Dobler and Ahrens 2008; Asharaf et al. 2012 ) is applied with a horizontal resolution of $0.5^{\circ} \times 0.5^{\circ}$ and with 32 vertical levels. The CCLM model is a nonhydrostatic RCM which uses terrain following height coordinates (Rockel et al. 2008), developed from the COSMO model, the current weather forecast model used by the German weather service (DWD).

According to Kaspar and Cubasch (2008), the CCLM model reaches an equilibrium state after few months in climate mode. Therefore, the first simulated year is excluded as spin-up period in the analysis. The model domain is adapted to cover the entire ACA (Fig. 2). All climate simulations are integrated for a 31-year time-slice which requires reasonable amount of computational time. Table 2 shows the model configuration used in this study. Recent data of the Earth's surface physical parameters (e.g., orography, land use, vegetation fraction, and land-sea mask) were used in all simulations. To consider the orbital configuration of the past millennium, the routine used by Prömmel et al. (2013) is applied in this study. This routine estimates the latitudinal and seasonal insolation at the top of the atmosphere based on Earth's orbital parameters.

The capability of the model of identifying the "exceptional" droughts during historical period was tested prior

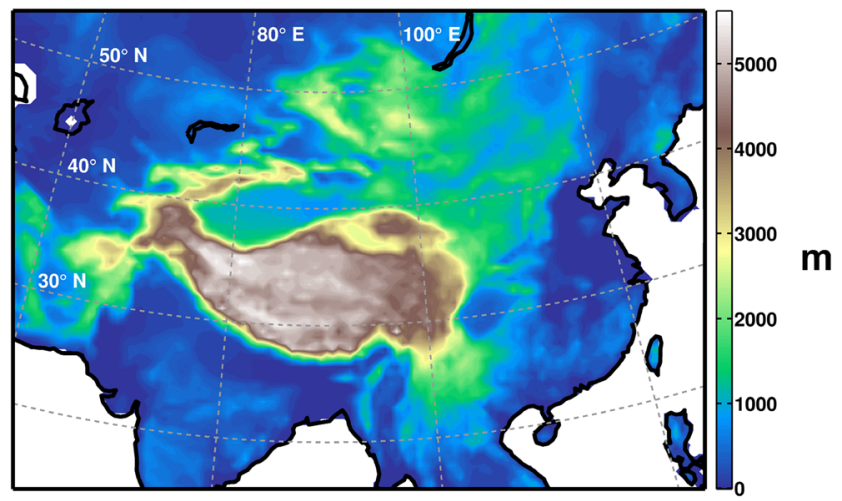

Fig. 2 Regional climate model's domain and the orography in meter
Table 2 COSMO-CLM model configuration parameters

\begin{tabular}{ll}
\hline Convection & Tiedtke \\
Lateral Relaxation Layer (rlwidth) & $800 \mathrm{~km}$ \\
Microphysics & Kessler \\
Radiation & Ritter and Geleyn \\
Rayleigh Damping Layer (rdheight) & $13 \mathrm{~km}$ \\
Robert-Asselin time filter (alphaass) & 0.7 \\
Time integration & Leapfrog, $\Delta t=150 \mathrm{~s}$ \\
Turbulence & Prognostic Turbulent \\
& Kinetic Energy (TKE) \\
\hline
\end{tabular}

to applying the model for simulating the past millennium. The recent climate (1979-2005) simulation was validated against the global data set of monthly PDSI (Dai-PDSI, hereafter) (Dai 2011a; 2011b; 2011c). Dai-PDSI is calculated from the Climate Research Unit (CRU) monthly surface air temperature (Jones et al. 2001) and precipitation data from National Centers for Environmental Prediction (NCEP). The soil texture-based water-holding-capacity map from Webb et al. (1993) is applied as available water capacity (AWC) in the Dai-PDSI calculation.

We have additionally calculated the PDSI from the output of CCLM, driven by ECMWF ERA-Inrerim reanalysis data at a resolution of approximately $0.7^{\circ}$. The results reveal that the COSMO-CLM is able to capture the PDSI patterns of the recent climate (not shown). The classical PDSI calculation method, following the one of Palmer (1965), is used to estimate the drought index from monthly surface air temperature and precipitation data from climate simulations. Dry area index is calculated based on the percentage of the grid points under dry conditions in each time-step. According to Dai (2013), the threshold of PDSI $<-2$ is suitable for such a consideration.

Following Zhao et al. (2014), the first principle component of $200 \mathrm{hPa}$ zonal wind over $30^{\circ}-50^{\circ} \mathrm{N}$ and $60^{\circ}-$ $100^{\circ} \mathrm{E}$ is used as the West Asian Subtropical Westerly Jet (WASWJ) displacement and the second one as the WASWJ strength. Expanding this domain up to $5^{\circ}$ does not affect the EOF analysis results. The EOF patterns from AGCM and RCM simulations were similar as in the study of Zhao et al. (2014) (not shown). The positive values of the standardized Principle Component (PC1) time-series (with unit standard deviation and zero mean) indicate an equator-ward shift of the WASWJ. The positive values of the standardized PC2 time-series reveal the strength of the WASWJ. As in the study of Zhao et al. (2014), the summer (JJA) season is considered in our analysis. The AGCM simulations were previously validated against the reconstructions of summer monsoon failure index (Fallah and Cubasch 2015; Polanski et al. 2014). 
a) MCA

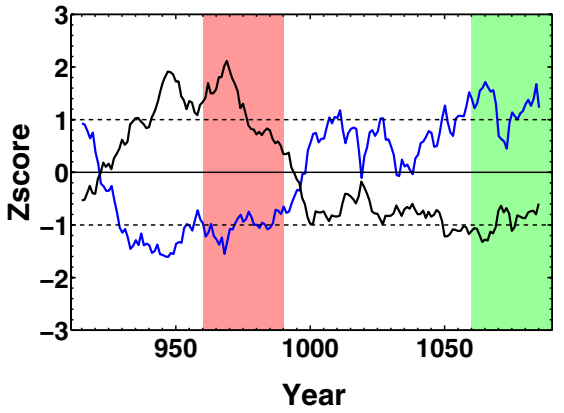

b) LIA

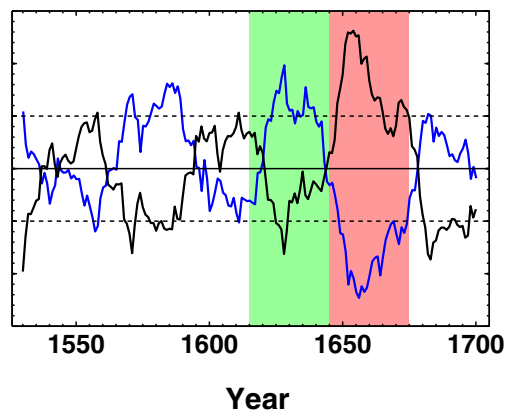

Red and green area indicates dry and wet periods selected for RCM simulations. Time-series are smoothed using a 31 years running mean filter
Fig. 3 Yearly mean of standardized (zero-mean and unit-variance) dry area (black line) and rainfall (blue line) anomalies of ECHAM5 simulation over arid Central Asia domain for a Medieval Climate Anomaly (MCA) 900-1100 and b Little Ice Age (LIA) 1515-1715. a) 2D Mixture model for MCA

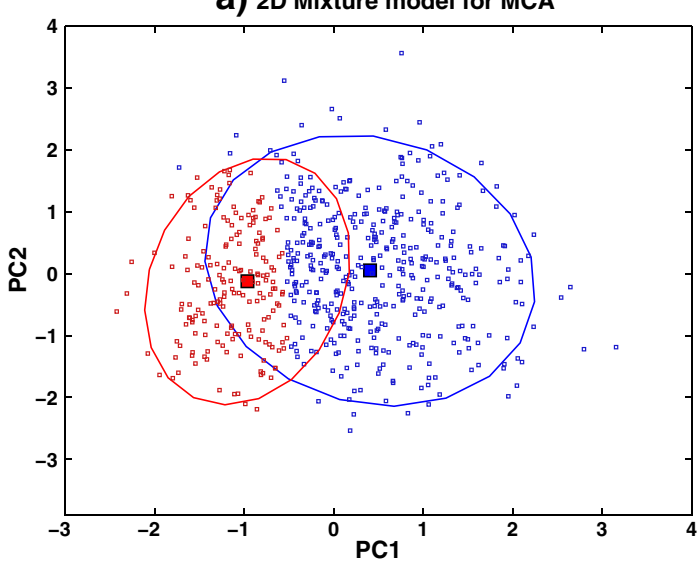

C) 2D Mixture model for LIA

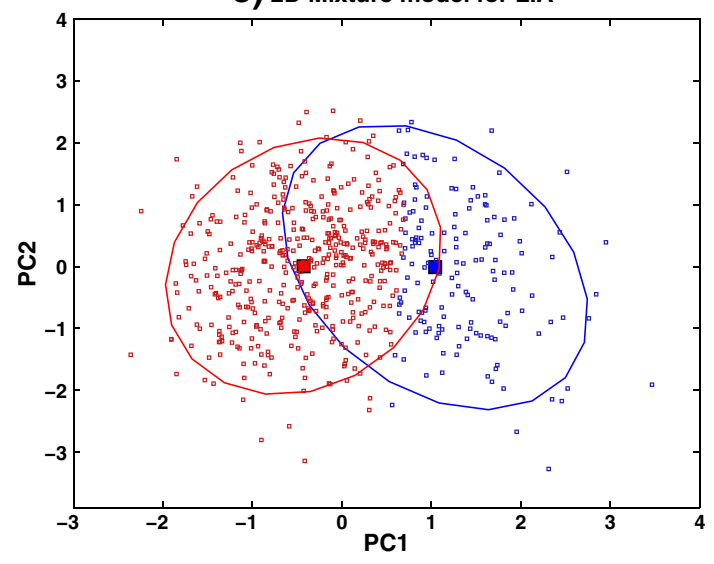

Fig. 4 Scatter plot of the leading two Principle Components (PCs) of $200 \mathrm{hPa}$ u-wind and centers of mixture components (filled squares) with their covariance ellipses from AGCM simulations for a Medieval Climate Anomaly (MCA) and c Little Ice Age (LIA) (blue color b) 2D Kernel PDF for MCA

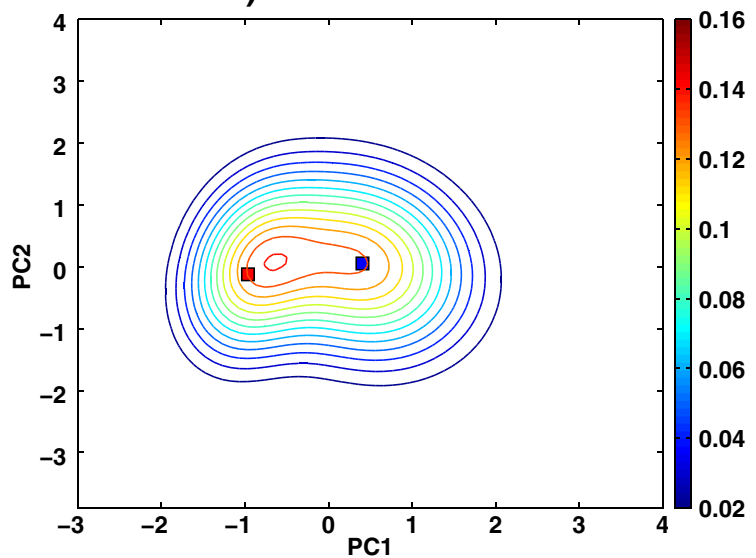

d) 2D Kernel PDF for LIA

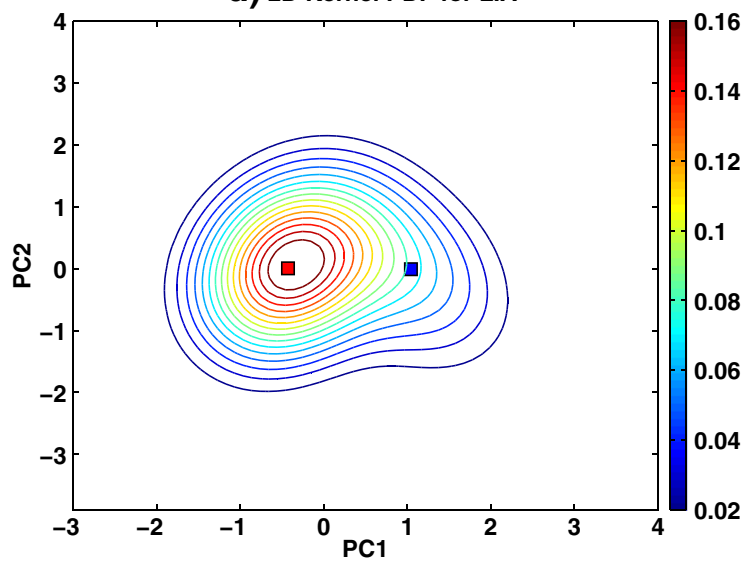

indicates the regime 1 and red color the regime 2) and Kernel Probability Density Function (PDF) estimates for the two PCs during the b Medieval Climate Anomaly (MCA) and d Little Ice Age (LIA) 


\section{Results}

\subsection{Time-slice selection}

The combined model-proxy comparison over the monsoon region with new paleo records revealed that the AOGCM was capable of capturing the majority of historical Asian droughts (Polanski et al. 2014; Fallah and Cubasch 2015)

Four different time-slices (two 30-years periods within each AGCM simulation) are selected to study the possible drivers of the extreme climate events during the past millennium (Table 1 and Fig. 3). The severity of the drought could be determined by its intensity, duration, and spatial coverage (Shen et al. 2007). Dry area time-series are used to identify the spatio-temporal extension of the drought across the past millennium. Additionally, monthly total rainfall anomaly over ACA is used as a metric for moisture variability. The region between $60^{\circ}-100^{\circ} \mathrm{E}$ and $35^{\circ}-50^{\circ} \mathrm{N}$ is used for calculating the rainfall anomaly over ACA to make sure that the selected area is located in the westerly-dominated ACA. Figure 3 shows the yearly average of standardized a) Regime $1 \mathrm{MCA}$

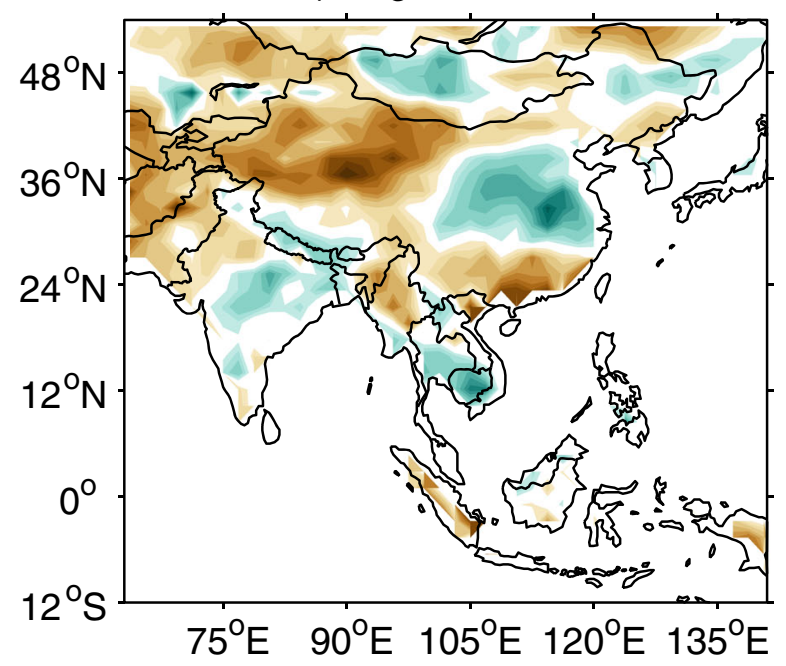

c) Regime 1 LIA

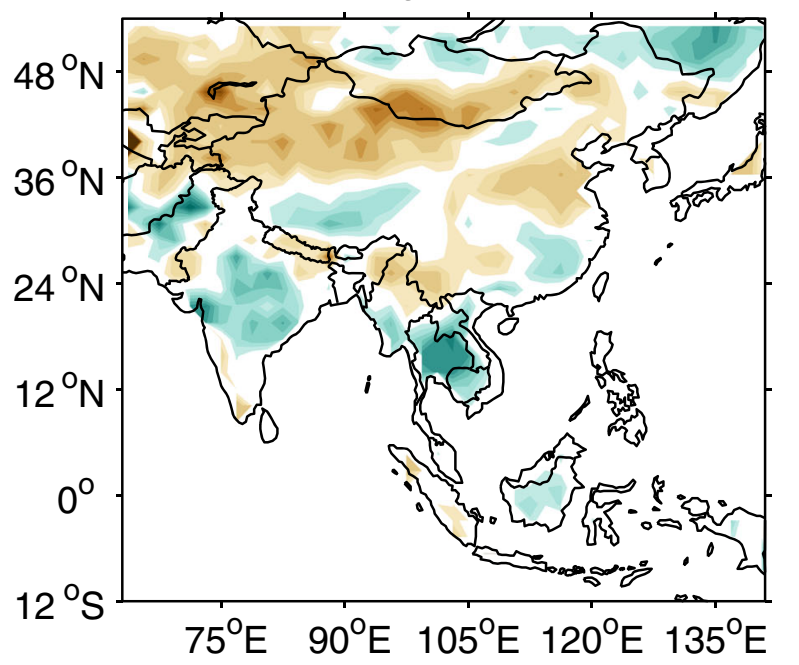

b) Regime 2 MCA

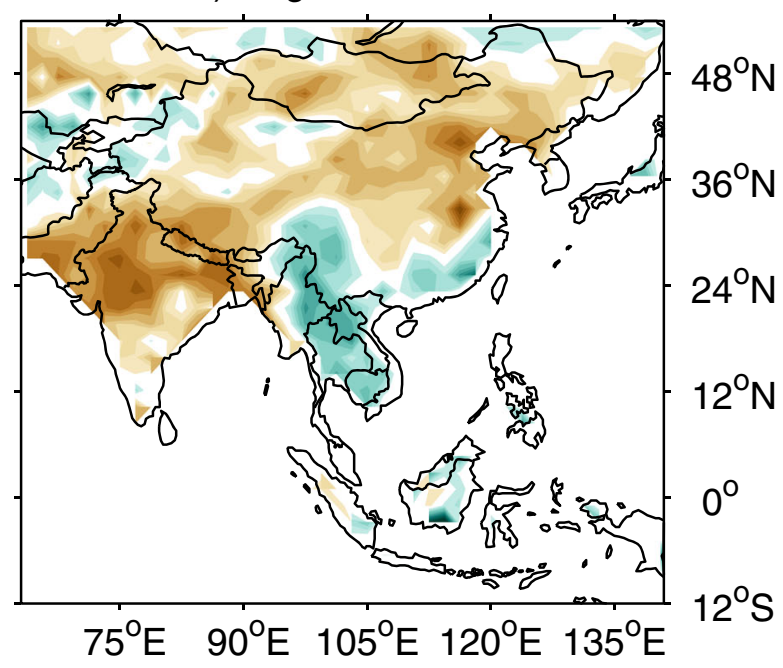

d) Regime 2 LIA

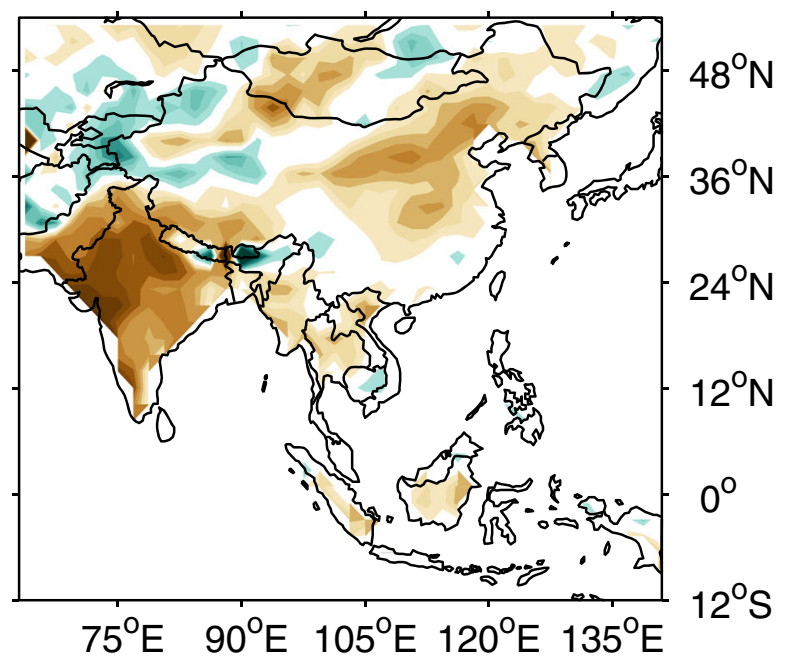

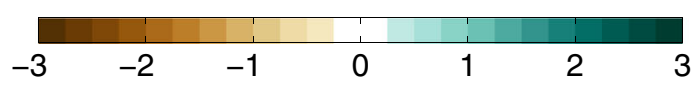

Fig. 5 The composites of the 30 nearest points to the left (regime 1) and right (regime 2) centers shown in Fig. 4a of the PDSI for a regime

the Medieval Climate Anomaly (MCA), c regime 1 during the Little Ice Age (LIA) and $\mathbf{d}$ regime 2 during the Little Ice Age (LIA) 
time-series of dry area (PDSI $<-2$ ) and rainfall anomalies for two AGCM time-slices (e.g., MCA and LIA) over the ACA domain. MCA presents two different trends with a "tipping point" in late ninth century, showing a shift to more wet conditions over ACA after 1000 AD. LIA exhibits clear fluctuation on intra-annual and inter-decadal time scales with a maximum for mid-seventeenth century. Times where the values cross \pm 1 represent particularly high amplitudes (extreme) events (red and green area in Fig. 3 present dry and wet spells, respectively).

\subsection{AGCM simulations}

We focus on the leading two PCs of $200 \mathrm{hPa}$ wind corresponding to the westerly jet displacement and strength to identify the structures of moisture changes over westerlydominated ACA. Figure 4a and $\mathrm{c}$ shows the phase-space of the leading two PCs of $200 \mathrm{hPa}$ westerly wind for AGCM simulations. The two dimensional Gaussian Kernel Probability Density Function (PDF) estimate of the two PCs is also shown in Fig. $4 \mathrm{~b}$ and d. Following previous studies using the Mixture model (Fallah and Cubasch 2015; Fallah and Sodoudi 2015; Hannachi 2007; Hannachi and Turner 2013; Turner and Hannachi 2010), the multivariate distribution is decomposed into two Gaussian distribution components. Each component is defined by a specific mean and covariance. The selection of two components is based on the fact that the Akaike information (Ljung 1999) is minimized using the two components. The centers of the mixture model (filled squares) and the covariance ellipses (solid lines) are shown in Figs. 4a and c for MCA and LIA periods, respectively. By using the two-component Gaussian mixture model, the phase states are clustered into two regimes. Red color indicates the states belonging to the left regime and blue color indicates the states related to the right regime (Fig. 4a and c). The two dimensional Kernel PDF estimate for the MCA period shows similar probabilities for the two regimes (Fig. $4 \mathrm{~b}$ and d). During the LIA, the left hand-side regime was more probable. We refer to left hand-side regime as regime 1 and to the right hand-side as regime 2 , hereafter.

To recognize the drought patterns associated with the preferred regimes, the composite of PDSI for the 30 nearest points to the centers of each component is calculated. Figure 5 presents the composites of PDSI for AGCM simulations. The PDSI patterns corresponding to regime 1 present dry spells over ACA with wet spells over India and East China. This pictures is reversed for regime 2. As seen in Fig. $4 \mathrm{a}$, the westerly jet displacement or PC1 is the major driver of the preferred regimes in AGCM simulations. The left hand-side or regime 1 is located in the negative values of PC1 or northward shift of westerly jet and regime 2 in the positive values or equator-ward shift of westerly jet.
Comparing the preferred regimes between MCA and LIA reveals that the dry conditions were more frequent during the MCA over ACA (Fig. 5). During the MCA, both regimes were equally probable, but during the LIA, regime 1 showed the highest probability (as shown in Fig. 4a). In contrast with the regime 1 of MCA, regime 1 of LIA shows values of PDSI greater than -2, which indicate near normal conditions. The PDSI composites related to different climate regimes point to the out-of-phase pattern between India and the ACA.

\subsection{RCM simulations}

To gain more information about the small scale climatic features of ACA during the past millennium, we consider the preferred regimes of the westerly jet from the RCM simulations. Figure 6 shows the centers of mixture components for AGCM and RCM simulations. The difference between the two regimes is larger during MCA. For example during the dry period of MCA, there is a displacement of about 2.5 for PC1 (jet's displacement) and 0.5 for PC2 (jet's strength) in the phase space. This behavior is more evident in the composites of the 30 closest points to the regime centers of dry MCA (Fig. 7). The dry MCA presents a changing pattern between a normal PDSI condition over most of the Asian domain (regime 1) and a dry pattern over monsoon regions with severe dry conditions over North India, Kazakhstan, and Tibet (Fig. 7b). The regime 2 of the wet MCA is expected to be more probable than regime 1 of the wet MCA (Table 3). During this regime, there is an increase in the wet conditions over East China, Kazakhstan, and North

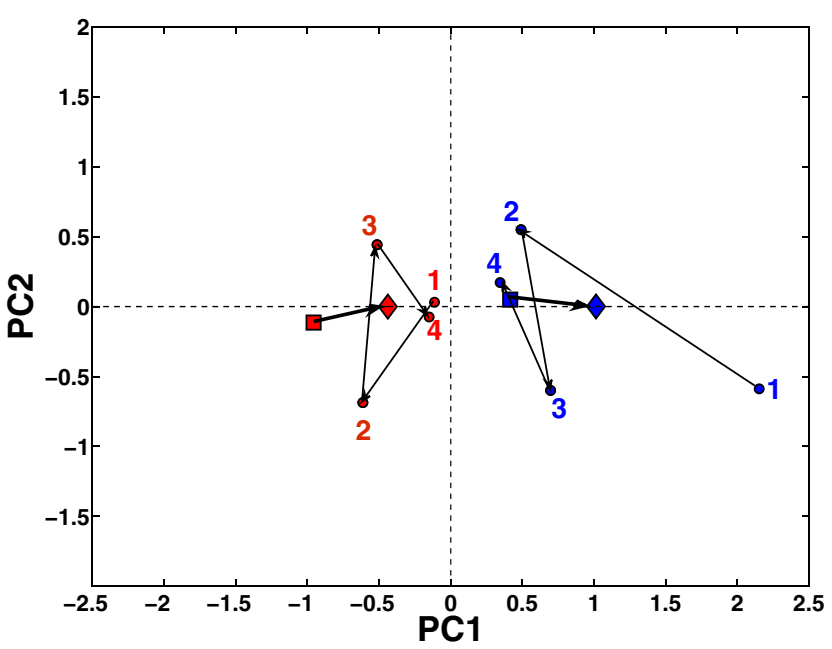

Fig. 6 The centers of mixture components for AGCM simulations with ECHAM5 (squares for Medieval Climate Anomaly (MCA) and diamonds for Little Ice Age (LIA)) and RCM simulations with CCLM (circles). Numbers indicate the different RCM simulations (ref. Table 3). Red colour indicates the regime 2 and blue colour the regime 1 
a) Regime 1 of dry MCA

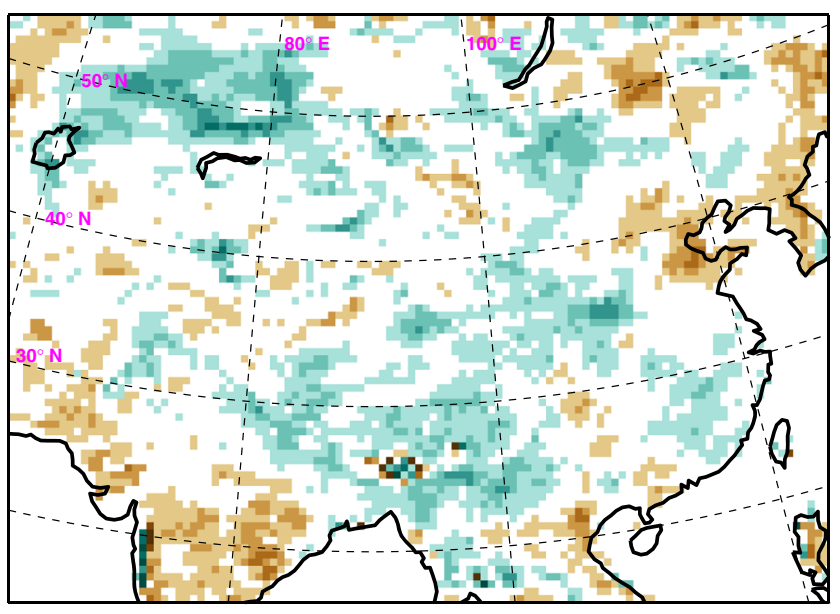

c) Regime 1 of wet MCA

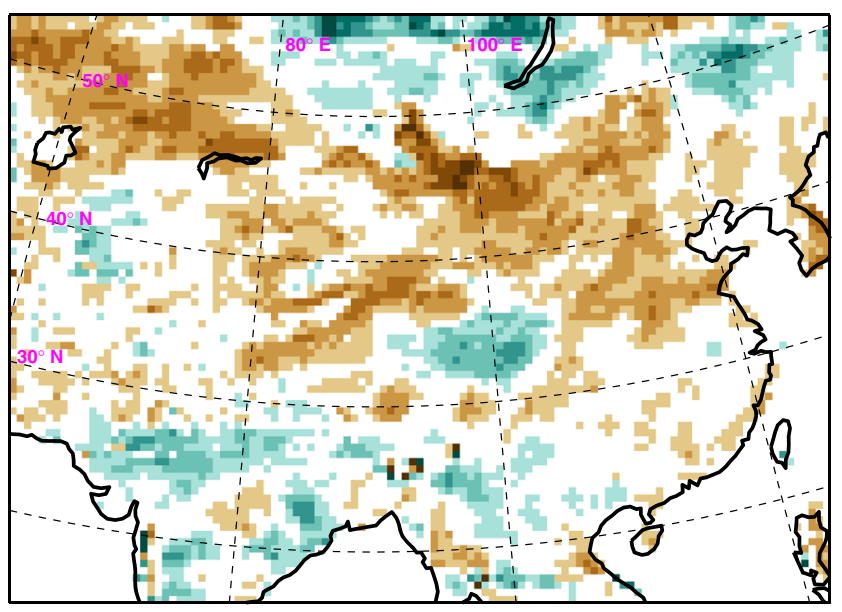

b) Regime 2 of dry MCA

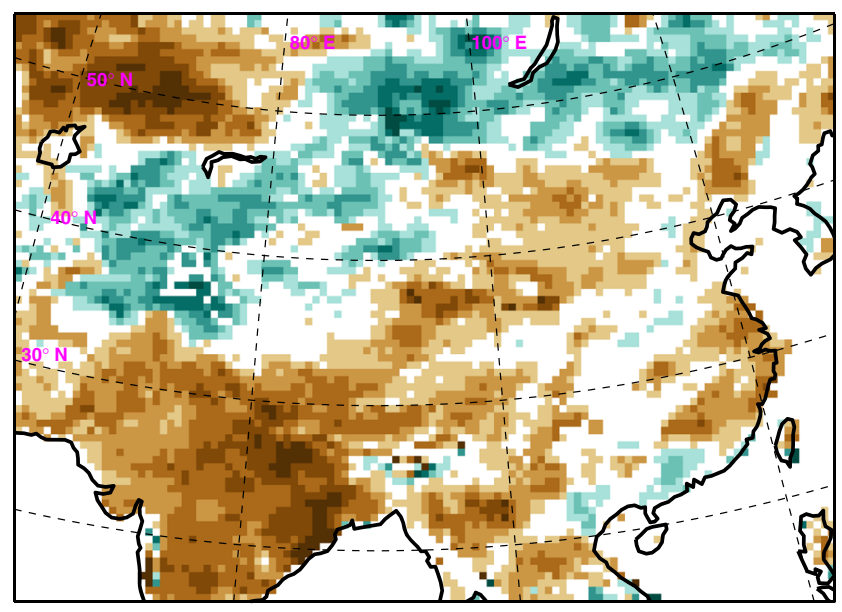

d) Regime 2 of wet MCA

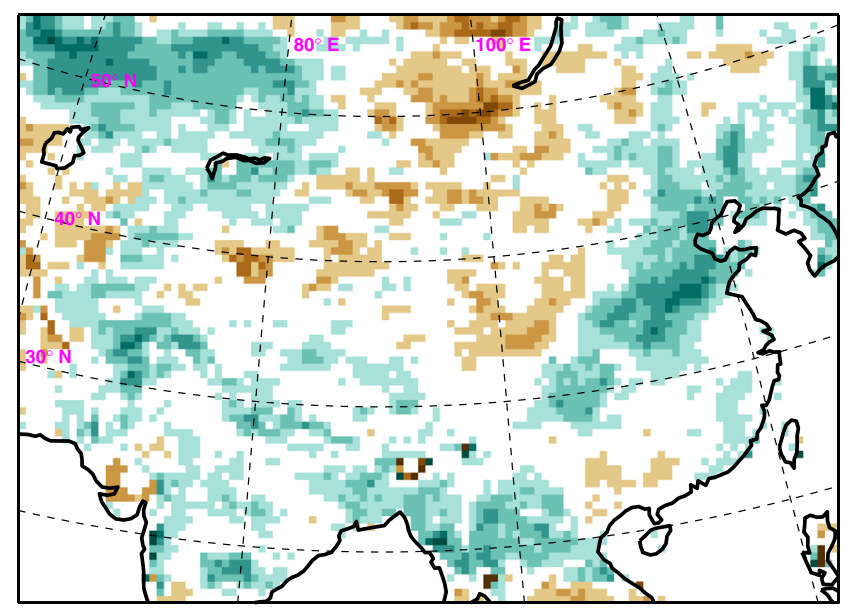

2

3

Fig. 7 The composites of the 30 nearest points to the left (regime 1) and right (regime 2) centers shown in Fig. 6 of the PDSI for a regime 1 of dry Medieval Climate Anomaly (MCA), b regime 2 of

dry Medieval Climate Anomaly (MCA), c regime 1 of wet Medieval Climate Anomaly (MCA), and d regime 2 of wet Medieval Climate Anomaly (MCA)

Table 3 The probability of the PDF's mode for different regimes of West Asian Subtropical Westerly Jet derived from RCM simulations

\begin{tabular}{lllll}
\hline $\begin{array}{l}\text { Probability } \\
\text { of PDF's mode }\end{array}$ & $\begin{array}{l}1=\text { dry MCA } \\
(960-990 \text { AD) }\end{array}$ & $\begin{array}{l}2=\text { wet MCA } \\
(1060-1090 \text { AD) }\end{array}$ & $\begin{array}{l}3=\text { wet LIA } \\
(1615-1645 \text { AD) }\end{array}$ & 0.18 \\
\hline Regime 1 & 0.20 & 0.14 & 0.13 & 0.22 \\
Regime 2 & 0.17 & 0.17 & 0.16 \\
\hline
\end{tabular}

Numbers in parenthesis indicate the simulation periods 


\section{a) Regime 1 of wet LIA}

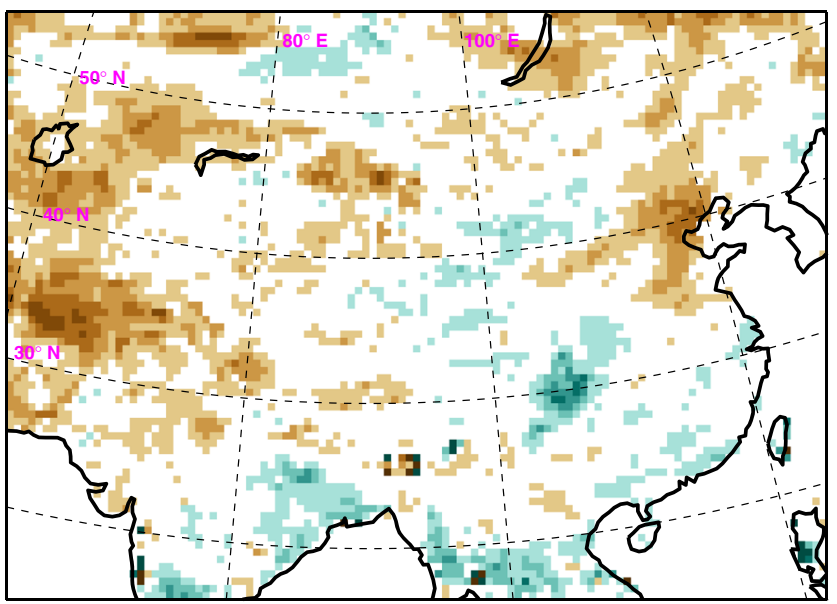

c) Regime 1 of dry LIA

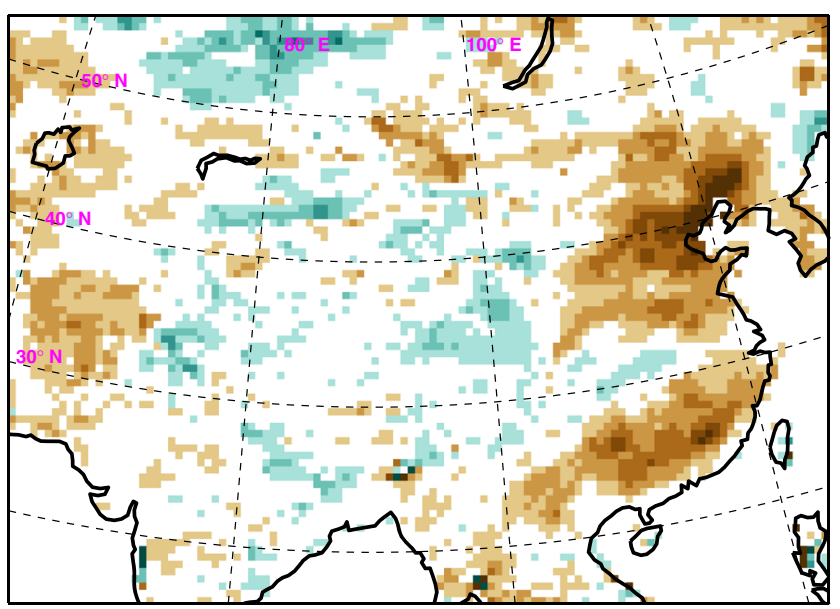

b) Regime 2 of wet LIA

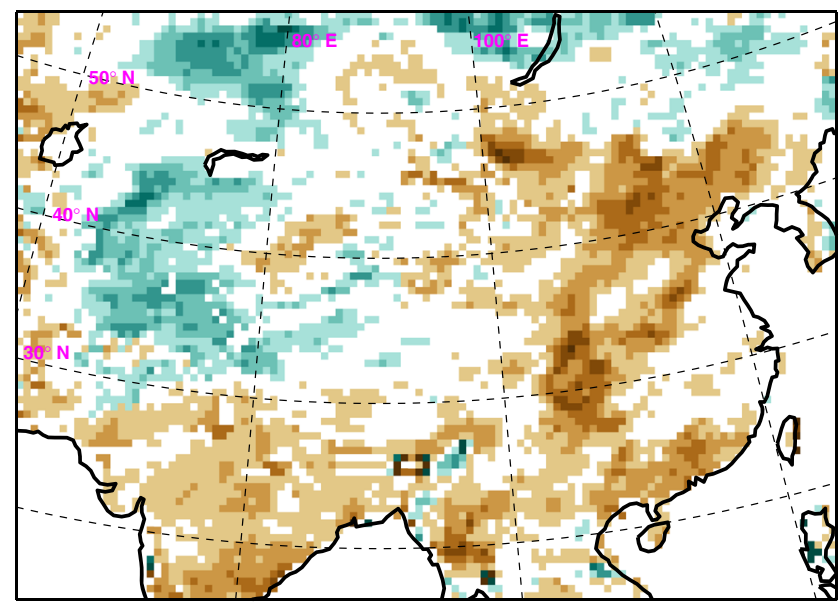

d) Regime 2 of dry LIA

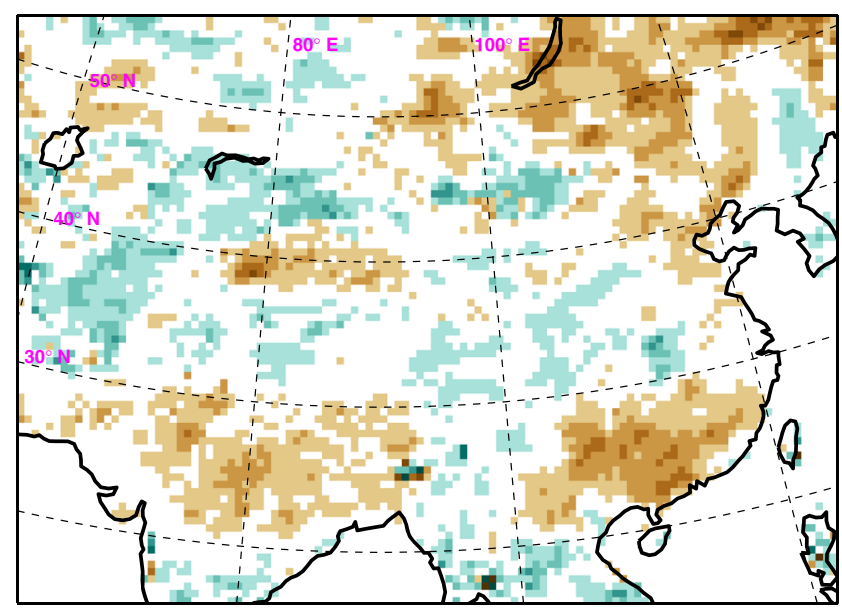

3

Fig. 8 The composites of the 30 nearest points to the left (regime 1) and right (regime 2) centers shown in Fig. 6 of the PDSI for a regime 1 of wet Little Ice Age (LIA), b regime 2 of wet Little Ice Age (LIA), c regime 1 of dry Little Ice Age (LIA), and d regime 2 of dry Little Ice Age (LIA)

India. Generally, the area over Kazakhstan shows a more sensitive response to the regimes of westerly jet during the MCA than during the LIA (Fig. 8).

During the LIA (Fig. 8), most of the Asian domain shows near normal conditions $(-2<\mathrm{PDSI}<2)$. The region around the Bohai Sea in East China, however, shows a dry spell for all the preferred regimes. The Kazakhstan region does not show the alternating pattern which existed throughout the MCA under changing regimes in westerly jet.

\section{Conclusions and discussion}

This study focuses on the dynamical drivers of the moisture changes in central Asia during the past millennium by using the ECHAM5 AGCM and COSMO-CLM RCM simulations. After evaluating the performance of models in detecting the wet and dry regimes of the observational and reanalysis data, we applied them for the climatic moisture extremes of the past millennium. Our model experiments covered different possible climate behaviors throughout the 
past millennium which could be clustered into wet and dry spells. By comparing the dynamical behavior of westerly jet in the selected time-slices, we studied the differences of internal variations of the climate system between extreme dry and wet spells.

Following Lorenz's idea of predictable climate response to different forcing, we analyzed the existence of a regime behavior in the westerly jet stream from model output. The evolution of the westerly jet showed a clear bimodal behavior. This regime behavior existed in both RCM and GCM simulations. The existence of the bimodality is mostly linked to the subtropical westerly jet displacement. The analysis based on the regional response of the hydro-climate of ACA to the large-scale climate forcing of the past millennium revealed that, during the MCA, this region was as sensitive as in the recent climate to the westerly jet stream. During the MCA the dipole pattern between India and ACA was not as pronounced as during the LIA. The sensitivity of moisture changes in Kazakhstan to westerly variability was stronger during the MCA. During the LIA East China showed dry patterns and Kazakhstan remained unaffected by the regimes of westerly jet changes.

We note that our simulations were based on a single driving model and the timing in the model may be uncertain, preventing us to make any conclusion about a specific year in the simulations. However, for 30-year time periods within MCA and LIA, the results depicted the averaged internally produced climate variability within these epochs. Using different driving GCMs for dynamical downscaling with RCMs will largely improve the certainty of the results. Regarding this, we suggest that considering more realizations using ensemble of driving GCMs and nested RCMs will produce a lot of added value in the results. This will lead to a larger coverage of the sample space. However, the computational costs will significantly increase in such approaches.

Finally, it should be emphasized that the main goal of this study was to investigate the possible drivers of regional hydro-climate changes during different periods of the past millennium and the speculations are based on simplified model set-ups. Any direct comparison of such climate simulations with proxy reconstructions may be misleading and would need further improvements.

Acknowledgments This research was supported and funded by German Federal Ministry of Education and Research (BMBF) research project Central Asian Climate Dynamics (CADY) as part of the joint research program "CAME" Central Asia: Monsoon Dynamics and Geo-Ecosystems" and the DFG research group FOR 1380 "HIMPAC". The authors thank the individual CADY/CAME and HIMPAC teams for permanent support and fruitful discussions. We acknowledge Edoardo Mazza for his precious critique and proofreading. Further, we thank Walter Acevedo, Emmanuele Russo, and Alexander Walter for their interesting discussions. The computational resources were made available by the German Climate Computing Center (DKRZ) through support from the BMBF. Finally, we acknowledge support by the German Research Foundation and the Open-Access Publication Funds of the Freie Universität Berlin.

\section{References}

Asharaf S, Dobler A, Ahrens B (2012) Soil moisture-precipitation feedback processes in the Indian summer monsoon season. J Hydrometeorol 13(5):1461-1474

Chen F-H, Chen J-H, Holmes J, Boomer I, Austin P, Gates JB, Wang N-L, Brooks SJ, Zhang J-W (2010) Moisture changes over the last millennium in arid central Asia: a review, synthesis and comparison with monsoon region. Quat Sci Rev 29(7-8): 1055-1068

Chen FH, Yu ZC, Yang ML, Ito E, Wang SM, Madsen DB, Huang XZ, Zhao Y, Sato T, Birks HJB, Boomer I, Chen JH, An CB, Wunnemann B (2008) Holocene moisture evolution in arid central Asia and its out-of-phase relationship with asian monsoon history. Quat Sci Rev 27(3-4):351-364

Cook ER, Anchukaitis KJ, Buckley BM, D'Arrigo RD, Jacoby GC, Wright WE (2010) Asian monsoon failure and megadrought during the last millennium. Science 328(5977): 486-489

Dai A (2013) Increasing drought under global warming in observations and models. Nature Clim Change 3(1):52-58

Dai AG (2011a) Characteristics and trends in various forms of the palmer drought severity index during 1900-2008. J Geophys ResAtmos 116:D12115

Dai AG (2011b) Characteristics and trends in various forms of the palmer drought severity index during 1900-2008. J Geophys ResAtmos 116:D12115

Dai AG (2011c) Drought under global warming: a review. Wiley Interdiscip Rev Clim Chang 2(1):45-65

Diffenbaugh NS, Bell JL, Sloan LC (2006) Simulated changes in extreme temperature and precipitation events at 6ka. Palaeogeogr Palaeoclimatol Palaeoecol 236(1-2):151-168

Dobler A, Ahrens B (2008) Precipitation by a regional climate model and bias correction in europe and south asia. Meteorologische Zeitschrift 17(4):499-509

Easterling DR, Meehl GA, Parmesan C, Changnon SA, Karl TR, Mearns LO (2000) Climate extremes: Observations, modeling, and impacts. Science 289(5487):2068-2074

Fallah B, Cubasch U (2015) A comparison of model simulations of asian mega-droughts during the past millennium with proxy reconstructions. Clim Past 11(2):253-263

Fallah B, Sodoudi S (2015) Bimodality and regime behavior in atmosphereocean interactions during the recent climate change. Dyn Atmos Oceans 70(0):1-11

Hannachi A (2007) Tropospheric planetary wave dynamics and mixture modeling: Two preferred regimes and a regime shift. J Atmos Sci 64(10):3521-3541

Hannachi A, Turner A (2013) Isomap nonlinear dimensionality reduction and bimodality of asian monsoon convection. Geophys Res Lett 40(8):1653-1658 
Hegerl GC, von Storch H, Hasselmann K, Santer BD, Cubasch U, Jones PD (1996) Detecting greenhouse-gas-induced climate change with an optimal fingerprint method. J Climate 9(10):22812306

Jones PD, Osborn TJ, Briffa KR (2001) The evolution of climate over the last millennium. Science 292(5517):662-667

Kaspar F, Cubasch U (2008) Simulation of east african precipitation patterns with the regional climate model clm. Meteorologische Zeitschrift 17(4):511-517

Lioubimtseva E, Cole R, Adams J, Kapustin G (2005) Impacts of climate and land-cover changes in arid lands of central asia. $\mathrm{J}$ Arid Environ 62(2):285-308

Ljung L (1999) System Identification: Theory for the users. PrinticeHall, Inc.

Lorenz EN (1969) How complicated is circulation of earths atmosphere. Ann N Y Acad Sci 163(A1)

Palmer TN (1993) Extended-range atmospheric prediction and the lorenz model. Bull Amer Meteor Soc 74(1):49-65

Palmer WC (1965) Meteorological drought. U.S. Weather Bureau, Washington, D.C. 20852 3(3):1-10

Polanski S, Fallah B, Befort DJ, Prasad S, Cubasch U (2014) Regional moisture change over india during the past millennium: a comparison of multi-proxy reconstructions and climate model simulations. Glob Planet Chang 122(0):176-185

Prömmel K, Cubasch U, Kaspar F (2013) A regional climate model study of the impact of tectonic and orbital forcing on african precipitation and vegetation. Palaeogeogr Palaeoclimatol Palaeoecol 369:154-162

Ramaswamy V, Schwarzkopf MD, Randel WJ, Santer BD, Soden BJ, Stenchikov GL (2006) Anthropogenic and natural influences in the evolution of lower stratospheric cooling. Science 311(5764):1138-1141

Rockel B, Will A, Hense A (2008) The regional climate model cosmo$\operatorname{clm}(\mathrm{cclm})$. Meteorologische Zeitschrift 17(4):347-348

Roeckner E, Brokopf R, Esch M, Giorgetta M, Hagemann S, Kornblueh L, Manzini E, Schlese U, Schulzweida U (2006) Sensitivity of simulated climate to horizontal and vertical resolution in the echam5 atmosphere model. J Climate 19(16):3771-3791

Ruti PM, Lucarini V, Dell'Aquila A, Calmanti S, Speranza A (2006) Does the subtropical jet catalyze the midlatitude atmospheric regimes? Geophys Res Lett 33(6):L06814
Santer BD, Taylor KE, Wigley TML, Johns TC, Jones PD, Karoly DJ, Mitchell JFB, Oort AH, Penner JE, Ramaswamy V, Schwarzkopf MD, Stouffer RJ, Tett S (1996) A search for human influences on the thermal structure of the atmosphere. Nature 382(6586):39-46

Santer BD, Wehner MF, Wigley TML, Sausen R, Meehl GA, Taylor KE, Ammann C, Arblaster J, Washington WM, Boyle JS, Brggemann W (2003) Contributions of anthropogenic and natural forcing to recent tropopause height changes. Science 301(5632):479483

Sato T, Tsujimura M, Yamanaka T, Iwasaki H, Sugimoto A, Sugita M, Kimura F, Davaa G, Oyunbaatar D (2007) Water sources in semiarid northeast Asia as revealed by field observations and isotope transport model. J Geophys Res 112(D17)

Shen C, Wang W-C, Hao Z, Gong W (2007) Exceptional drought events over eastern china during the last five centuries. Clim Chang 85(3-4):453-471

Slingo J, Palmer T (2011) Uncertainty in weather and climate prediction. Philos Trans R Soc A Math Phys Eng Sci 369(1956):47514767

Steppeler J, Doms G, Schattler U, Bitzer HW, Gassmann A, Damrath U, Gregoric G (2003) Meso-gamma scale forecasts using the nonhydrostatic model $\mathrm{lm}$. Meteorol Atmos Phys 82(1-4):75-96

Stocker T, Qin D, Plattner G-K, Tignor M, Allen S, Boschung J, Nauels A, Xia Y, Bex V, Midgley P (2013) Ipcc, 2013: Climate change 2013: The physical science basis. contribution of working group $i$ to the fifth assessment report of the intergovernmental panel on climate change. Technical report. Cambridge University Press, Cambridge, United Kingdom and New York, NY, USA

Thompson RS, Anderson KH (2000) Biomes of western north America at 18,000, 6000 and $0 \mathrm{c}-14 \mathrm{yr}$ bp reconstructed from pollen and packrat midden data. J Biogeogr 27(3):555-584

Turner AG, Hannachi A (2010) Is there regime behavior in monsoon convection in the late 20th century? Geophys Res Lett 37:L16706

Webb RS, Rosenzweig CE, Levine ER (1993) Specifying land surface characteristics in general-circulation models - soil-profile data set and derived water-holding capacities. Glob Biogeochem Cycles 7(1):97-108

Zhao Y, Wang M, Huang A, Li H, Huo W, Yang Q (2014) Relationships between the west asian subtropical westerly jet and summer precipitation in northern xinjiang. Theor Appl Climatol 116(3-4):403-411 